\title{
PENERAPAN KAIDAH RUKHSHAH PADA KASUS HUKUM KELUARGA
}

\author{
Norcahyono \\ FAI Universitas Muhammadiyah Palangka Raya \\ e-mail: norcahyono.arribangi@gmail.com
}

\begin{abstract}
Abstrak
Penelitian ini dilatarbelakangi oleh pemikiran yang menganggap rukhshah sebagai keringanan mutlak yang diberikan syariat tanpa memperhatikan beberapa syarat dan kaidah-kaidah yang dibenarkan. Berdasarkan permasalahan tersebut peneliti tertarik untuk mengungkap hakikat rukhshah dan penerapannya pada kasus hukum keluarga menggunakan metode deskriptif-analitik. Berdasarkan fokus masalah penelitian ini menghasilkan tiga hal: (I) Hakekat rukhshah adalah keringanan-keringanan yang telah diberikan syariat islam sebagai bentuk keringanan dalam melaksanakan syariat islam berdasarkan kondisi atau syarat yang dibenarkan, bukan untuk tujuan melakukan perbuatan maksiat. (2) Kaidah

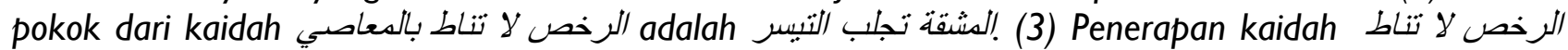
يالs pada kasus hukum keluarga akan membantu para Mukallaf bersikap lebih bijak dan bertanggungjawab ketika mengambil rukhshah sebagai bentuk keringanan yang diberikan syariat, bukan untuk tujuan mendhalimi dan maksiat.
\end{abstract}

\section{Kata kunci: kaidah rukhshah, hukum, keluarga}

This research is motivated by the idea that considers rukhshah as an absolute relief given by the Shari'a without paying attention to several conditions and justified rules. Based on these problems, researchers are interested in revealing the nature of rukhshah and its application to family law cases using descriptive-analytic methods. Based on the focus of the problem, this research produces three things: (I) The essence of rukhshah is the waivers that have been given by Islamic law as a form of relief in carrying out Islamic law based on justified conditions or conditions, not for the purpose of committing immoral acts.

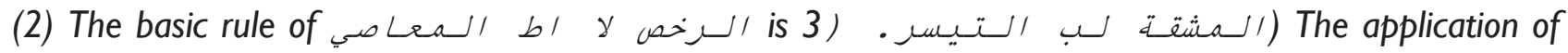

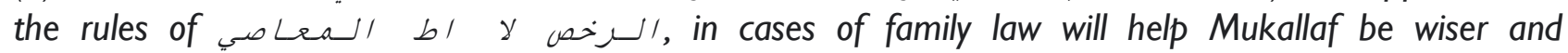
responsible when taking rukhshah as a form of relief given by the Shari'a, not for the purpose of wrongdoing and immorality.

Keywords: rukhshah rules, law, family 


\section{A. PENDAHULUAN}

Kaidah الرخص لا تناط بالمعاصي memiliki arti; Keringanan itu tidak memberi peluang dalam berbuat kemaksiatan

Diantara tujuan adanya rukhshah (keringanan) dalam hukum islam adalah untuk menjaga agar keringanan yang diberikan oleh syariat tidak disalahgunakan untuk melakukan perbuatan maksiat. As-Subki dalam bukunya al-Asybah wa an-Nadhair menyebutkan contoh penerapan kaidah keringanan sebagaimana berikut; "seorang yang melakukan perjalanan jauh tidak mendapatkan keringanan bolehnya shalat qashar atau shalat jama' jika niat perjalanannya itu untuk berbuat maksiat, seperti bepergian untuk merampok, membunuh dan sebagainya. Dalam kasus hukum keluarga, misalnya seorang perempuan yang berbuat nusyuz kemudian kabur dari suaminya, maka dalam perjalanannya yang jauh itu tidak mendapatkan keringanan untuk melaksanakan shalat qashar atau shalat jama'.

Dalam hukum islam seseorang akan mendapatkan suatu rukhshah dalam melaksanakan kewajibannya sebagai seorang mukallaf jika memenuhi beberapa syarat.

Pertama; Mukallaf. Mukallaf adalah pihak yang memikul atau terkena taklif (beban hukum). Menurut Wahbah az-
Zuhaili Mukallaf adalah seseorang yang telah baligh (dewasa) dan berakal yang dengan akalnya itu ia berkemampuan mengetahui fungsi dan yang difungsikannya, dan dengan pengetahuannnya itu ia mengerjakan seluruh kewajiban yang dibebankan kepadanya." Pada konsep yang dikemukakan ini terkandung tiga unsur pada diri seorang Mukallaf yang satu sama lain tidak dapat dipisahkan. Unsurunsur tersebut adalah manusia, telah dewasa (baligh), dan berakal sehat.

Kedua; Tidak dimaksudkan dan dicampuri dengan perbuatan maksiat. rukhshah merupakan bentuk hukum pengecualian dari hukum asalnya, maka dalam prakteknya tidak boleh dicampuri dengan perbuatan maksiat.

Ketiga; Adanya udzur bagi mukallaf. Uzur dalam kajian ushul fikih adalah beberapa kondisi seperti sangat mendesak (dharurah), kesulitan diluar kemampuan (masyaqqah), kebutuhan yang mendesak (hajah) dan dalam keadaan terpaksa (ikrah). Selain adanya uzur terdapat kondisi lain yang menyebabkan seseorang memperoleh rukhshah seperti dalam keadaan sedang bepergian (as-safar), sakit (al-maradh), lupa (an-nisyan), keliru (al-khata), tidak tahu (al-jahl), Kesulitan yang umum (umum al-balwa), dan kondisi kekurangan (an-naqsh). 
Tujuan diberikan rukhshah dalam ajaran islam bagi Mukallaf dalam melaksanakan beban hukum adalah untuk menghilangkan kesulitan-kesulitan yang sedang dihadapi.

Mengingat pentingnya memahami kaidah rukhshah dan penerapannya dalam hukum islam, terkhusus tentang hukum keluarga, penulis tertarik untuk menuangkan hasil pemikiran dalam bentuk penelitian pustaka tentang Penerapan Kaidah Rukhshah pada Kasus Hukum Keluarga dengan fokus pada beberapa permasalahan berikut (I) bagaimana hakekat rukhshah dalam hukum islam? (2) apa kaidah pokok dari kaidah الرخص لا تناط بالمعاصي? Bagaimana penerapan kaidah الرخص لا تناط بالمعاصي pada kasus hukum keluarga?

\section{B. METODE}

Jenis penelitian ini adalah penelitian kepustakaan (library reseach). Dalam penelitian ini mencari, menelaah dan mengkaji tema Kaidah Rukhshah (keringanan) dalam hukum islam melalui berbagai sumber literatur. Penelitian bersifat deskriptif-analitik, yaitu mendeskripsikan hakekat Rukhshah (keringanan) dalam hukum islam kemudian dianalisis penerapannya dalam beberapa kasus hukum keluarga.

\section{PEMBAHASAN}

\section{Hakekat Rukhshah dalam Hukum Islam}

Secara etimologi, rukhshah berarti kemudahan, kelapangan, dan kemurahan. Sedangkan kata rukhshah menurut terminologi adalah hukum yang ditetapkan berbeda dengan dalil berdasarkan adanya udzur.

Abdul Wahab Khallaf sebagai representasi ulama kontemporer mendefinisikan rukhshah dengan tiga definisi. Pertama, rukhshah merupakan sebuah hukum yang disyari'atkan Allah sebagai bentuk keringanan bagi seorang mukallaf dalam keadaan tertentu yang menuntut adanya keringanan. Kedua, rukhshah adalah hukum yang disyariatkan oleh Allah dalam keadaan tertentu karena adanya alasan yang memberatkan. Ketiga, membolehkan sesuatu yang dilarang karena adanya dalil, beserta tetap adanya dalil yang melarang.

Dari pengertian diatas, pengertian rukhshah secara sederhana adalah keringanan-keringanan yang diperoleh seorang mukallaf yang memiliki kondisi kesulitan diluar kemampuan (masyaqqah) yang menuntut keringanan berdasarkan kebutuhan yang sangat mendesak atau kondisi seorang mukallaf yang mengambil keputusan hukum yang ringan berdasarkan legitimasi dalil syar'i. 
Rukhshah sebagai bentuk keringanan dari hukum islam mendapatkan legitimasi dari dua sumber utama hukum islam yaitu dari al-Qur'an dan hadis.

I) Al-Qur'an

$$
\text { Q.S al-Hajj ayat 78; }
$$

dan berjihadlah kamu pada jalan Allah dengan Jihad yang sebenarbenarnya. Dia telah memilih kamu dan Dia tidak menjadikan kesukaran untukmu dalam agama...

$$
\begin{aligned}
& \text { Q. S al-Baqarah ayat } 286
\end{aligned}
$$

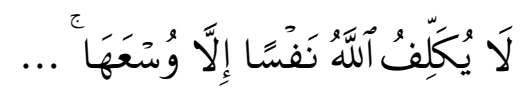

Allah tidak membebani seseorang melainkan sesuai dengan kesanggupannya...

2) Hadis

Dari Ibnu Umar Rasulullah Shallallahu 'alaihi wa sallam bersabda:

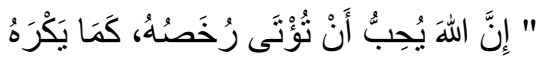

$$
\begin{aligned}
& \text { أَنْ تُؤْنَى مَعْصِيَتُهُ" }
\end{aligned}
$$

\section{Sesungguhnya Allah Senang} untuk dikerjakan rukshah-Nya (keringanan-keringanan-Nya) sebagaimana Dia benci dikerjakan kemaksiatan untuk-Nya.

Dalam ilmu fikih, kesukaran yang membawa kepada rukhshah (keringanan) itu dapat dibenarkan jika seorang Mukallaf dalam beberapa kondisi yaitu:

I) Sedang dalam perjalanan (alSafar). Misalnya, boleh qasar shalat, buka puasa, dan meninggalkan shalat jumat.

2) Keadaan sakit. Misalnya boleh tayammum ketika sulit memakai air, shalat fardu sambil duduk, tidak puasa di bulan ramadhan dengan kewajiban qadha setelah sehat, ditundanya pelaksanaan had sampai terpidana sembuh, wanita yang sedang menstruasi.

3) Keadaan terpaksa yang membahayakan kepada kelangsungan hidupnya. Setiap akad yang dilakukan dalam keadaan terpaksa, maka akad tersebut tidak sah seperti jual beli, gadai, sewa-menyewa, karena bertentangan dengan prinsip ridha (rela), merusak atau menghancurkan barang orang lain karena dipaksa.

4) Lupa (al-Nisyan). Misalnya, seseorang lupa makan dan minum pada waktu puasa, lupa membayar utang tidak diberi sanksi, tetapi bukan pura-pura lupa.

5) Ketidaktahuan (al-Jahl). Misalnya, orang yang baru masuk Islam karena tidak tahu, kemudian 
makan makanan yang diharamkan, maka dia tidak dikenai sanksi.

6) Umum al-balwa. Kesukaran yang umum terjadi. Misalnya, kebolehan bai al-Salam (uangnya dulu, barangnya belum ada). Kebolehan dokter melihat kepada bukan mahramnya demi untuk mengobati, sekedar yang dibutuhkan dalam pengobatan. Percikan air dari tanah yang mengenai sarung untuk shalat.

7) Kekurang mampuan bertindak hukum (al-Naqsh). Misalnya, anak kecil, orang gila, orang dalam keadaan mabuk. Dalam ilmu hukum, yang berhubungan dengan pelaku ini disebut unsur pemaaf, termasuk di dalamnya keadaan terpaksa atau dipaksa.

Sedangkan bentuk rukhshah (keringanan) karena adanya masyaqqah (kesulitan diluar kemampuan) juga terbagi menjadi beberapa bentuk, yaitu:

I) Rukhshah isqath, yaitu keringanan dalam bentuk penghapusan seperti tidak wajib shalat bagi wanita yang sedang mentruasi atau nifas. Tidak wajib haji bagi yang tidak mampu (istitha'ah).

2) Takhfif tanqish, yaitu keringanan berupa pengurangan, seperti shalat Qasar dua rakaat yang asalnya empat rakaat.
3) Takhfif ibdal, yaitu keringanan berupa penggantian, seperti wudhu atau mandi wajib diganti dengan tayammum, atau berdiri waktu shalat wajib diganti dengan duduk karena sakit.

4) Takhfif taqdim, yaitu keringanan dengan cara didahulukan, seperti jama' taqdim di Arafah; mendahulukan mengeluarkan zakat sebelum haul (batas waktu satu tahun); mendahulukan mengeluarkan zakat fitrah di bulan Ramadhan; jama' taqdim bagi yang sedang bepergian yang menimbulkan masyaqqah dalam perjalanannya.

5) Takhfif ta'khir, yaitu keringanan dengan cara diakhirkan, seperti shalat jama' ta'khir di Muzdalifah, qadha saum Ramadhan bagi yang sakit, jama' takhir bagi orang yang sedang dalam perjalanan yang menimbulkan masyaqqah dalam perjalanannya.

6) Takhfif tarkhis, yaitu keringanan karena rukhshah, seperti makan dan minum yang diharamkan dalam keadaan terpaksa, sebab bila tidak, bisa membawa kematian.

7) Takhfif taghyirm, yaitu keringanan dalam bentuk berubahnya cara yang dilakukan, seperti shalat pada waktu khauf (kondisi tidak 
aman), misalnya pada waktu perang.

Menurut Jaih Mubarak para ulama membagi hukum rukshah sebagaimana berikut;

I) Wajib. Contohnya: Makan bangkai hukum asal adalah haram, tetapi karena kondisi darurat, sekiranya ia tidak makan akan menyebabkan kematian, maka dalam keadaan ini hukumnya adalah wajib.

2) Sunnah. Misalnya: Shalat dzuhur bila dilakukan dua rakaat maka hukumnya adalah haram, tetapi karena bepergian jauh, maka hukumnya berubah menjadi sunnat, sebab ia diperbolehkan mengqasar shalatnya.

3) Mubah. Misalnya: Uang panjar (uang yang terlebih dahulu dibayarkan, sebelum ada barang) hukumnya tidak boleh, tetapi karena sangat dibutuhkan hukumnya berubah menjadi mubah.

4) Ada yang khilaf al-Aula. Misalnya: Shalat jamak bagi orang yang sedang tidak bepergian hukumnya haram, tetapi karena sakit, maka berubah menjadi khilaf al-Aula.

5) Makruh. Misalnya: Sahalat qasar asal hukumnya tidak boleh, tetapi karena bepergian yang hanya 80 km, maka hukumnya menjadi makruh.
2. Kaidah Pokok dari Kaidah الرخص لا<smiles></smiles>

Kaidah pokok dari kaidah الرخص لا , المشقة تجلب التيسر adalah , "Kesukaran itu dapat menarik kemudahan".

Al-Masyaqqah menurut bahasa (etimologis) adalah al-ta'ab yaitu kelelahan, kepayahan, kesulitan, dan kesukaran. Sedangkan kata al-taysir secara bahasa (etimologis) adalah kemudahan. Kesukaran yang dapat menarik kemudahan maksudnya adalah kesukaran menyebabkan adanya suatu kemudahan, karena hukum yang dilaksanakan menyulitkan mukallaf, baik pada diri dan lingkup sekitarnya terdapat kesukaran, maka syariat memudahkannya sehingga beban tersebut berada di bawah kemampuan mukallaf tanpa kesukaran. Hukum-hukum yang dalam penerapannya menimbulkan kesukaran dan kesulitan bagi mukallaf (subjek hukum), maka syariah memudahkannya sehingga mukkalaf mampu melaksanakannya tanpa tanpa kesukaran dan kesulitan.

Adapun kaidah-kaidah yang dapat diambil dari kaidah pokok tersebut selain الرخص لا تناط بالمعاصي adalah sebagaimana berikut: 


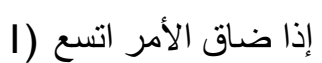

"Apabila suatu perkara menjadi sempit maka hukumnya meluas"

Kaidah ini berbicara tentang rukshah ketika dalam situasi kesempitan atau kesulitan. Seperti, boleh berbuka puasa pada bulan Ramadhan karena sakit atau bepergian jauh. Sakit dan bepergian jauh merupakan suatu kesempitan, maka hukumnya menjadi luas yaitu kebolehan berbuka. Akan tetapi, bila orang sakit itu sembuh kembali, maka hukum wajib melakukan puasa itu kembali wajib.

Dari kaidah ini muncul kaidah kedua yaitu: Apabila suatu perkara menjadi meluas maka hukumnya menyempit”. Kaidah ini juga dimaksud untuk tidak meringankan yang sudah ringan. Oleh karena itu kaidah ini digabungkan menjadi satu, yaitu: إذا ضاق الأمر اتسع Apabila suatu perkara menjadi sempit maka hukumnya meluas dan apabila suatu perkara menjadi meluas maka hukumnya menyempit". Kaidah ini juga menunjukkan fleksibilitas hukum Islam yang bisa diterapkan secara tepat pada setiap keadaan. Kaidah yang semakna dengan kaidah ini كل ما تجاوز عن حده إنعكس إلى ضده:adalah "Setiap yang melampaui batas maka hukumnya berbalik kepada yang
sebaliknya”Atau kaidah: ما جاز لعذر بطل Apa yang dibolehkan karena uzur (halangan) maka batal (tidak dibolehkan lagi) dengan hilangnya halangan tadi" Contoh penerapannya seperti wanita yang sedang menstruasi dilarang shalat dan puasa. Larangan tersebut menjadi hilang bila menstruasinya berhenti. Kewajiban melaksanakan shalat fardhu dan puasa ramadhan kembali lagi dan boleh lagi melakanakan shalat sunnah dan puasa sunnah.

2) إذا تعذر الأصل يصار إلى البدل

"Apabila yang asli sukar dikerjakan maka berpindah kepada penggantiannya"

Contohnya: tayammum sebagai pengganti wudhu. Dalam figh siyasah, kaidah di atas banyak diterapkan terutama dalam hal yang berhubungan dengan tugas-tugas kepemimpinan. Misalnya, ada istilah PJMT (pejabat yang melaksanakan tugas), karena pejabat yang sesungguhnya berhalangan, maka diganti oleh petugas lain sebagai penggantinya.

3) ما لا يمكن التحرز منه منه معفو ا عنه

"Apa yang tidak mungkin menjaganya (menghindarkannya), maka hal itu dimaafkan".

Contohnya: pada waktu sedang berpuasa, kita berkumur-kumur, maka tidak mungkin terhindar dari 
rasa air di mulut atau masih ada sisasisa. Darah pada pakaian yang sulit dibersihkan dengan cucian.

4) إذا تعذرت الحقيقة يصار إلى المجاز

"Apabila suatu kata sulit diartikan dengan arti yang sesungguhnya, maka kata tersebut berpindah artinya kepada arti kiasannya".

Contohnya: seseorang berkata: "saya wakafkan tanah saya ini kepada anak kyai Ahmad". Padahal semua tahu bahwa anak kyai tersebut sudah lama meninggal, yang ada adalah cucunya. Maka hal ini, kata anak harus diartikan cucunya, yaitu kata kiasannya, bukan kata sesungguhnya. Sebab, tidak mungkin mewakafkan harta kepada yang sudah meninggal dunia.

5) إذا تعذر إعمال الكلام يهمل

"Apabila sulit mengamalkan suatu perkataan, maka perkataan tersebut ditinggalkan"

Contohnya: apabila seseorang menuntut warisan dan mengaku bahwa dia adalah anak dari orang yang meninggal, kemudian setelah ditelti dari akta kelahirannya, ternyata dia lebih tua dari orang yang meninggal yang diakuinya sebagai ayahnya. Maka perkataan orang tersebut ditinggalkan dalam arti tidak diakui perkataannya.

يعتفر في الدوام ما لا يعتفر في الإبتداء (6)
"Bisa dimaafkan pada kelanjutan perbuatan dan tidak bisa dimaafkan pada permulaannya".

Contohnya: orang yang menyewa rumah yang diharuskan membayar uang muka oleh pemilik rumah. Apabila sudah habis masa waktu penyewaan, dan dia ingin memperbarui sewaannya, maka dia tidak perlu membayar uang muka lagi. Demikian pula halnya untuk memperpanjang izin perusahaan, seharusnya tidak diperlukan lagi persyaratan-persyaratan yang lengkap seperti waktu mengurus izinnya pertama kali.

7) يعتفر في الإبتداء مالا يعتفر في الدوام

"dimaafkan pada permulaan tapi tidak dimaafkan pada kelanjutannya".

Hal ini terjadi pada kasus tertentu yaitu orang yang melakukan perbuatan hukum karena tidak tahu bahwa perbuatan tersebut dilarang. Contohnya: pria dan wanita melakukan akad nikah karena tidak tahu bahwa di antara keduanya dilarang melangsungkan akad nikah baik karena nasab, mushaharah (persemendaan), maupun karena sepersusuan. Selang beberapa tahun, baru diketahui bahwa antara pria dan wanita itu ada hubungan nasab atau hubungan pesemendaan, atau sepersusuan, yang menghalangi sahnya pernikahan. Maka pernikahan 
tersebut harus dipisah dan dilarang melanjutkan kehidupan sebagai suami istri. Contoh lain: seorang yang baru masuk Islam minum minuman keras karena kebiasaannya sebelum masuk Islam dan tidak tahu bahwa minuman semacam itu dilarang (haram). Maka orang tersebut dimaafkan untuk permulaannya karena ketidaktahuannya. Selanjutnya, setelah dia tahu bahwa perbuatan tersebut adalah haram, maka ia harus menghentikan perbuatan haram tersebut.

8عتئفر في التو ابع مالا يعتفر في غير ها

"Dapat dimaafkan pada hal yang mengikuti dan tidak dimaafkan pada yang lainnya".

Contohnya: penjual boleh menjual kembali karung bekas tempat beras, karena karung mengikuti kepada beras yang dijual. Demikian pula boleh mewakafkan kebun yang sudah rusak tanamannya karena tanaman mengikuti tanahyang diwakafkan.

3. Penerapan Kaidah الرخص لا تناط pada Kasus Hukum Keluarga

Berikut adalah penerapan kaidah pada beberapa kasus hukum keluarga.

I) Hukum melihat calon yang ingin dinikahi; bagi lelaki/perempuan melihat calon orang yang ingin dinikahinya adalah dibenarkan oleh syariat, bahkan tanpa sepengetahuannya supaya semakin yakin untuk menikahinya. Izin yang diperkenankan oleh syariat adalah bagi lelaki boleh melihat sendiri calon perempuan yang ingin dinikahinya sebatas melihat muka dan telapak tangannya. Kebolehan ini adalah rukshah dari syariat, namun jika kebolehan ini dimanfaatkan untuk hal yang selebihnya seperti melihat yang lainnya selain muka dan telapak tangan, apalagi memegang megang sebelum akad nikah maka ini tidak dibenarkan oleh syariat, dan dihukumi sebagai perbuatan maksiat.

2) Hukum memukul isteri; dalam syariatnya islam membolehkan seorang suami memukul istrinya ketika dirasa sedang nusyuz, dalam rangka memberikan pengajaran supaya istri sadar dan segera mengakhiri sikap nusyuznya tersebut. Namun, jangan memukul muka dan jangan pula melukainya. Kebolehan ini merupakan rukshah yang dibenarkan oleh nash, namun kebolehan tersebut jika dilakukan dengan melampiaskan kemarahan bukan untuk tujuan memberikan pengajaran atau upaya menyadarkan istri, seperti 


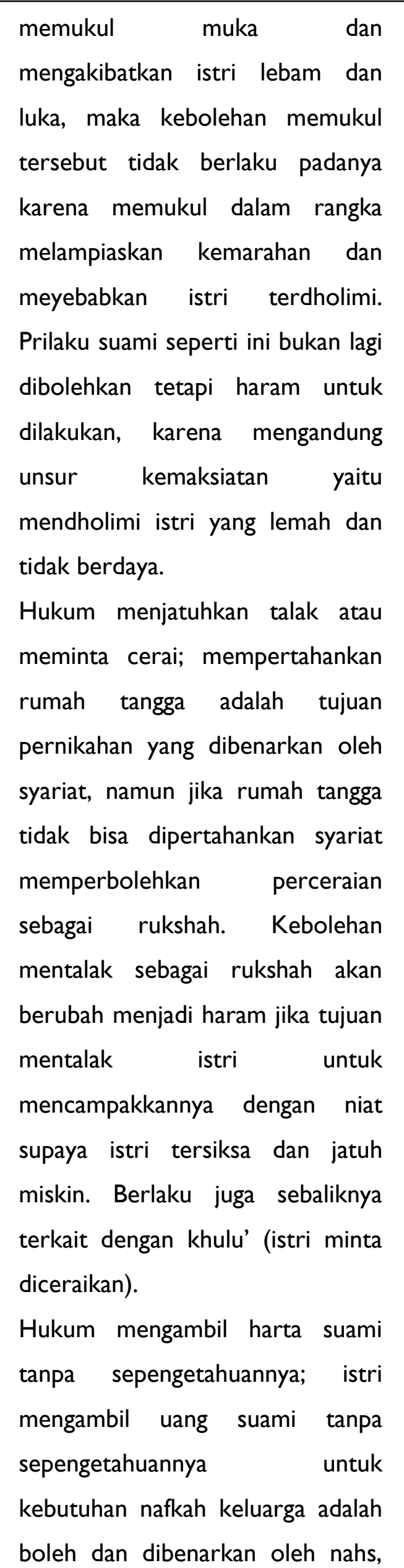

kebolehan tersebut sebagai rukshah karena keperluan primer untuk kebutuhan makan dan sandangnya. Tetapi jika mengambil uang suami melebihi dari kebutuhan yang ia perlukan maka ini tidak boleh bahkan bisa terjerumus kedalam kemaksiatan, yaitu menipu dan khiyanat terhadap harta suami.

5) Hukum berpoligami; Poligami adalah rukshah bagi orang-orang tertentu yang memerlukan dengan syarat adil, ketika orang memerlukan poligami sebagai solusi maka itu rukshah bagi orang tersebut. Tetapi jika orang yang tidak memerlukan poligami sebagai solusi dalam kehidupan rumah tangganya maka ruksah kebolehan tersebut tidak berlaku padanya. Misalnya seorang suami mempunyai istri dan istrinya telah ideal menjadi ibu rumah tangga dan hidupnya penuh dengan kebahagiaan. Berjalannya waktu suami ingin berpoligami dikarena tergoda dengan wanita lain dan ingin menikahinya, tetapi istri tersebut tidak setuju dengan keputusan suaminya. Kemudian suami mengambil langkah untuk tetap menikah lagi. Berjalannya waktu hubungan dengan istri pertamanya tidak lagi harmonis, 
bahkan suami tidak lagi memberikan nafkah kepada istrinya karena ketidakmampuannya bersikap adil. Pada keadaan ini poligami sebagi rukshoh tidak lagi dibenarkan oleh syariat sebab dengan mengambil rukshoh tersebut mengakibatkan suami mengabaikan hak istri pertamanya juga sebab tidak mampu adil dan ini kemudharatan yang diperbuat oleh suami terhadap istri. Jadi bagi suami yang tidak mampu berpoligami memaksakan diri untuk tetap berpoligami dengan dalih poligami dibenarkan oleh syariat, maka ini bisa menjerumuskan kepada maksiat. Sebagaimana kaidah yang dibahas bahwa Keringanan yang diberikan syariat itu tidak memberi peluang dalam berbuat kemaksiatan.

Berdasarkan hasil penelitian, sebagaimana permasalahan yang dibahas kesimpulan yang diperoleh adalah sebagaimana berikut:

I. Hakekat rukhshah adalah keringanan-keringanan yang telah diberikan syariat islam sebagai bentuk keringanan dalam melaksanakan syariat islam berdasarkan kondisi atau syarat yang dibenarkan, bukan untuk tujuan melakukan perbuatan maksiat.

2. Kaidah pokok dari kaidah الرخص لا المشقة تجلب التيسر adalah تناط بالمعاصي. 3. Penerapan kaidah الرخص لا تناط بالمعاصي, pada kasus hukum keluarga akan membantu para Mukallaf bersikap lebih bijak dan bertanggungjawab ketika mengambil rukhshgb. $\mathbf{K}$ sebagai bentuk keringanan yang diberikan syariat, bukan untuk $\mathbf{i}_{\mathbf{i}}^{\mathbf{s}}$ tujuan mendhalimi dan maksiat. $\mathbf{m}$

Berdasarkan hasil penelitiă $\mathbf{p}_{\mathbf{u}}$ diatas, rukhshah (keringanan) diberlkan oleh syariat jangan sampai disalah̆ untuk melakukan perbuatan maksiat. jika syariat rukhshah diambil oleh seseorang tidak sesuai $\mathbf{n}$ dengan kebutuhan dan kondiși yang dibenarkan syariat akan mangantar 
seseorang kepada perbuatan maksiat. Sehingga kaidah ini memberikan kontribusi bagi yang mempelajarinya agar menempatkan dan mengambil rukhshah yang diberikan syariat sebagaimana porsi dan kondisi yang telah disyaratkan.

\section{DAFTAR PUSTAKA}

Abu Zahrah, Muhammad. Ushul Figh, cet, II. (Jakarta: Pustaka Firdaus, 2008).

Ibn Bakr al-Suyuti, Jalal al-Din 'Abd alRahman. Al-Asybāh wa al-Nazāhir (Beirut: Dār Kitab al-'Arabi, 1987).

al-Zuhaili, Wahbah. Nazharriyyah al-daruurah al-Syar'iyyah Muqaaranah ma'a al-qanuun alWad'i (Damaskus: Maktabah al-Farābi, 1982).

Ariyadi, Ariyadi. "Metodologi Istinbath Hukum Prof. Dr. Wahbah Az Zuhaili." lurnal Hadratul Madaniyah 4.I (20I7): 32-39.

Ariyadi, Ariyadi. "Tindak Pidana Pelaku Eksploitasi Seksual Pada Anak Di Tinjau Dari Hukum Positif." lurnal Hadratul Madaniyah 5.2 (20I8): 73-88.

Ariyadi, Ariyadi. "Tindak Pidana Pelaku Eksploitasi Seksual pada Anak Menurut Hukum Islam." Jurnal Hadratul Madaniyah 6.I (2019): 43-67.

Ash-Shiddieqy, Hasbi. Falsafah Hukum Islam (Cet.IV; Jakarta: PT.Bulan Bintang, 1990).

As-Subki, al-Asybaah wa an-Nadhaair (Beirut: Daar al-Kutuub al-Ilmiyah, 199I).

az-Zuhaili, Wahbah. Ushuul al-Figh al-Islami, (Damaskus: Daar al-Fikr, 2005).

az-Zuhailii, Wahbah. al-Figh al-Islaami wa Adillatuh, (Damaskus: Daar al-Fikr, 1985).

Djazuli, A. Kaidah-kaidah Fikih, Kaidah-kaidah Hukum Islam dalam Menyelesaikan Masalahmasalah yang Praktis, Jakarta : Kencana, 2007.

Kementerian Agama Republik Indonesia, AlQur'an dan Terjemahannya (disertai tema penjelas kandungan ayat), cet. I, (Jakarta: CV. EL MISYKAAH, 20I5).
Khallaf, Abd. Wahab, Ilmu Usul Figh, (Dar AlQalam, Kuwait, tt.).

Musbikin, Imam. Qawaa'id al-Fiqhiyyah (Cet.l; Jakarta: PT.Raja Grafindo Persada, 200I).

Mubarok, Jaih. Kaidah Fiqih, Sejarah dan Kaidah asasi (Cet.l; Jakarta: PT.Raja Grafindo Persada, 200I). 